\title{
GRONWALL INEQUALITIES ON TIME SCALES
}

\author{
Fu-Hsiang Wong, CheH-ChiH YeH AND Chen-Huang Hong
}

Abstract. The authors use several different methods to extend Gronwall's inequality to more general cases on a time scale. Two applications are also given.

Mathematics subject classification (2000): 26D15.

Key words and phrases: Gronwall inequality, LaSalle's inequality and Bihari's inequality, time scale.

\section{REFERENCES}

[1] R. P. Agarwal, M. Bohner And A. Peterson Inequalities on time scales, A survey, Math. Inequal. \& Appl., 4, 4 (2001), 535-557.

[2] D. D. Bainov, P. S. Simeonov, Integral Inequalities and Applications, Kluwer Academic Publishers, Dordrecht/Boston/London, 1992.

[3] I. BIHARI, A generalization of lemmas of Bellman and its application to unique problem of differential equations, Acta Math. Acad. Sci., Hungar. 7, (1956), 71-94.

[4] M. Bohner, A. Peterson, Dynamic Equations On Time Scales, Birkhäuser, Boston /Basel/ Berlin, 2001.

[5] U. D. Dhongade, S. G. DeO, Some generalizations of Bellman-Bihari integral inequalities, J. Math. Anal. Appl., 44, (1973), 218-226.

[6] T. H. GRONWALL, Note on the derivative with respect to a parameter of the solutions of a system of differential equations, Ann. Math. 20, (1919), 292-296.

[7] S. Hilger, Analysis on measure chains - A unified approach to continuous and discrete calculus, Results Math. 18, (1990), 18-56.

[8] B. KAYMAKCALAN, Existence and comparisom results for dynamic systems on a time scale, J. Math. Anal. Appl., 172, (1993), 243-255.

[9] B. Kaymakcalan, S. A. OzGun And A. Zafer, Gronwall and Bihari type inequalities on time scales, In proceeding of the 2nd Internations (Veszprem, 1995), Gordon and Breach, Amsterdam (1997), 481-490.

[10] J. P. LASALlE, Uniqueness theorems and successive approximations, Ann. Math., 50, (1949), 722-730.

[11] V. Lakshmikantham, S. LeEla, 'Differential and Integral Inequalities, Vol I, Academic Press, New York, 1969.

[12] V. LaKshmikantham, S. Sivasundaram AND B. KaYmaKCAlan, Dynamic Systems on Measure Chains, Kluwer Academic, Boston, 1996.

[13] B. G. PACHPATte, On some integral inequalities similar to Bellman-Bihari inequalities, J. Math. Anal. Appl., 49, (1975), 794-802.

[14] B. G. PAChPATTE, A note on Gronwall-Bellman inequality, J. Math. Anal. Appl., 44, (1973), 758-762.

[15] C. C. YEH, Bellman-Bihari integral inequalities in several independent variables, J. Math. Anal. Appl., 87, (1982), 311-321.

[16] C. C. YEH, Discrete inequalities of Gronwall-Bellman type in $n$ independent variables, J. Math. Anal. Appl., 105, (1985), 322-332.

[17] C. C. YEH, Discrete inequalities of Gronwall-Bellman type in $n$ independent variables, II, J. Math. Anal. Appl., 106, (1985), 282-285. 